\title{
DMS Mathematical Sciences Research Institutes Update
}

\author{
Michael Vogelius and Henry Warchall
}

The National Science Foundation (NSF) Division of Mathematical Sciences (DMS) supports a portfolio of distinguished investments in Mathematical Sciences Research Institutes. These institutes are important components of the US mathematical sciences infrastructure. The institutes serve as national resources for advancing research, increasing the impact of the mathematical sciences, engaging with scientific opportunities in other fields, enabling the mathematical sciences to respond to national needs, and expanding the US talent base engaged in mathematical and statistical research. Recently the NSF has decided to ramp down funding of two of the mathematics institutes. This update provides some information about this portfolio of unique DMS investments and places it in the context of the entire DMS awards portfolio.

\section{Background}

DMS provides major support for eight national research institutes:

- American Institute of Mathematics (AIM) in San Jose, California (DMS support for workshops and the "structured quartet research ensembles" program begun in 2001).

- Institute for Advanced Study (IAS) in Princeton, New Jersey (DMS support for postdoctoral and midcareer visitors, begun in 1997).

Michael Vogelius is director of the Division of Mathematical Sciences at the NSF. His email address is mvoge $1 \mathrm{i}$ u@nsf. gov. Henry Warchall is DMS senior advisor. His email address is hwarcha1@nsf.gov.

For permission to reprint this article, please contact: reprint-permission@ams.org.

DOI: http://dx.doi.org/10.1090/noti1322
- Institute for Computational and Experimental Research in Mathematics (ICERM) in Providence, Rhode Island, begun in 2009.

- Institute for Mathematics and its Applications (IMA) in Minneapolis, Minnesota, begun in 1981.

- Institute for Pure and Applied Mathematics (IPAM) in Los Angeles, California, begun in 1998.

- Mathematical Biosciences Institute (MBI) in Columbus, Ohio, begun in 2001.

- Mathematical Sciences Research Institute (MSRI) in Berkeley, California, begun in 1981.

- Statistical and Applied Mathematical Sciences Institute (SAMSI) in Research Triangle Park, North Carolina, begun in 2001.

In addition, DMS contributes support to the National Institute for Mathematical and Biological Synthesis (NIMBioS) in Knoxville, Tennessee, and also provides funding to four international institutes to support participation of US-based researchers in their activities:

- Banff International Research Station (BIRS) (Canada).

- Mathematisches Forschungsinstitut Oberwolfach (MFO) (Germany).

- Institute des Hautes Études Scientifiques (IHÉS) (France).

- Fields Institute (Canada).

DMS support for the two oldest institutes, IMA and MSRI, dates back to the early 1980s. These two institutes were funded continuously by DMS for the next decade, undergoing periodic merit review but without facing competition from other applicants. By the 1990s, however, NSF policy had evolved to require that long-running programs be exposed to open competition. The first program solicitation for DMS institute proposals was issued in 1997. As a result of that competition, the award establishing support for IPAM was granted, while support for IMA and MSRI was continued. 
In 1999 the National Research Council released a report [1] that underscored the importance of research institutes in mathematics and made recommendations for the evolution of DMS-supported institutes. In 2001, as a result of a subsequent open competition, DMS established institute support for AIM, MBI, and SAMSI. Following a subsequent open competition, ICERM was established in 2009. During this expansion of the portfolio of DMS institutes, support for existing DMS institute investments was maintained.

The result of the open DMS institute competitions in the past two decades has been to create a suite of mathematical sciences research institutes of substantial breadth in terms of both program style and emphasis area. The institutes play a unique role among DMS investments as convening bodies that catalyze mathematical sciences research through programs that attract leading players to assemble and exchange ideas. They are unmatched in their ability to host programs of substantial duration, international scale, and prestige. The institutes provide venues and logistical support for these gatherings, but more importantly, institute directors and advisory boards work tirelessly to develop top-quality programming that pushes the cutting edge of research opportunities. Institute activities significantly help shape the progress of research in the mathematical sciences.

In view of the distinguished role that the institutes play on a national scale in advancing research in the mathematical sciences, DMS supervision of the institute awards in recent years has evolved from management of individual institute awards to management of the suite of awards as a portfolio. DMS oversees and makes recommendations regarding the portfolio through the efforts of a management team. For their part, the institute directors meet regularly to collaborate, to coordinate plans for programming, and to keep DMS apprised of issues of common concern or interest.

\section{The Mathematical Sciences Research Institutes in the Context of DMS Investments}

The mission of the Division of Mathematical Sciences is to support research at the frontiers of discovery in mathematical sciences and to support training of the next generation of mathematical sciences researchers. DMS is responsible for programs with a total 2015 budget of over US\$225 million available for research investments. These programs support activities that expand the knowledge base of the mathematical sciences through research awards to individual investigators and small groups, workforce training grants, and the portfolio of national mathematical sciences research institutes. DMS invests in discovery in mathematics and statistics; promotes interdisciplinary connections across all fields of science, engineering, and technology; and cultivates a diverse and capable community of researchers, students, and professionals. These top investment priorities-discovery, connections, and community-are essential components of the innovation engine that drives the nation's economy in the twenty-first century.

Meeting this mission requires constant effort on the part of DMS staff to identify the most effective ways to invest the resources furnished by US taxpayers. The Division establishes investment priorities that support the development of the mathematical sciences and at the same time increase the amount of resources available to the mathematical sciences community. Because there are continuously emerging new and important opportunities for DMS investments, and because the growth of the DMS budget is frequently tied to new opportunities, the Division engages in continual rebalancing of its investment portfolio.

Consequently, members of the DMS scientific staff make difficult choices every day. Many activities compete for funding: supporting established individuals, supporting junior investigators, investing in diversity, building infrastructure for research (such as institutes, stand-alone conferences, and research groups), and training future generations of mathematical scientists. Many topical areas compete as well; there are choices between long-term versus short-term goals and between activities of immediate relevance to national initiatives versus investments in the development of basic knowledge. The Division wishes to support all of these, and the job of the DMS scientific staff is to find the right balance.

Not only is the Division's scientific staff continually making choices among proposals for activities that are before them, they are also trying to anticipate the future, foster growth, and nurture creativity. Funding opportunities come and go: even within the DMS disciplinary research programs, which may seem like a constant feature of the divisional investment portfolio, the individuals and the topics supported undergo dramatic changes over the years. For all these reasons, the Division is not able to indefinitely support any person, area, facility, or program, even if there could be good reasons to do so.

Decisions concerning portfolio balance remain for the most part invisible to the mathematical sciences community overall, unless the decisions concern larger DMS investments. Such visible recent decisions concerning larger investments include the VIGRE, RNMS, EXTREEMS-QED, and MCTP programs that have been discontinued, as well as the decisions this article hopes to put in context, namely, to make awards that ramp down funding for two of the mathematical sciences research institutes, IMA and MBI. 


\section{The DMS Awards Portfolio}

In more detail, the DMS awards portfolio has three major components: (1) the unsolicited Individual Investigator awards (IIA) (73.5 percent), (2) the Mathematical Sciences Research Institute awards (13.7 percent), and (3) Workforce/Infrastructure awards (W/IA) (12.8 percent). The percentages in parentheses are the approximate percentages of the total US\$218 million available for DMS research investments in 2014. The Individual Investigator component is managed by eight different disciplinary programs: Algebra and Number Theory, Analysis, Computational Mathematics, Statistics, etc. The awards of this component typically support single investigators, but are also given to small groups of investigators. In addition to support for research projects, this component also provides almost US\$6 million in support of conferences each year. It is the oldest and probably best-known component of the DMS portfolio.

The Workforce/Infrastructure component is perhaps the least known; it provides funding for dedicated activities to help train the next generation(s) of mathematical scientists and also for activities that support the growth of the mathematical sciences community as a whole. Programs include the Mathematical Sciences Postdoctoral Research Fellows (MSPRF) program, the Research Training Group (RTG) program, the Enriched Doctoral Training (EDT) program, the Research Experiences for Undergraduates (REU) program, and the NSF-CBMS Regional Research Conferences in the Mathematical Sciences program.

It is well known that the DMS budget was significantly cut in 2013 in connection with the government-wide sequestration. Moreover, even though the budget has seen partial restorations in 2014 and 2015, it has still not recovered to the absolute dollar amount of 2012. Since 2012, funding for the IIA program has stayed largely constant, though there has been significantly reduced spending on Focused Research Groups (FRGs), from seven awards in 2012 to four awards in 2014. In combination with a higher number of proposals and the inflationary increased costs of individual awards, the essentially level IIA budget has resulted in a significantly lower funding success rate in this program. To mention numbers: in the last fiscal year (2014) DMS received 2,313 proposals for IIA (not counting proposals for conference funding) and made 620 awards, for a funding success rate of 26.8 percent. The success rate prior to 2012 was commonly in the low thirties. The W/IA program has shrunk considerably, with a significantly lower number of RTG awards. In the two-year period 2011-2012 DMS made 14 RTG awards, whereas the number in the two-year period 2013-2014 was 10. These circumstances mean that DMS currently has to decline many IIA and W/IA proposals of extremely high value and potential impact. Funding for the institutes program has stayed constant these last three years, although it has seen a significant expansion since its beginning with two institutes more than thirty years ago.

\section{The Mathematical Sciences Research Institutes Review Process}

The DMS institutes program has significantly more flexibility in terms of duration of continued funding than the centers programs funded by other NSF divisions. Since the institutes do not concentrate on a single research topic but are intended to reinvent themselves year after year by developing new programs with changing organizers and participants, they are not subject to the (tenyear) sunset provision that centers are. A DMS institute grant is of five years' duration; any existing institute may submit a proposal for a renewal and could in principle continue to receive DMS funding indefinitely. Every ten years, the competition is open to proposals for "new" institutes-this situation is traditionally referred to as a competitive renewal situation. However, it is important to point out that the evaluation criteria used in competitive and noncompetitive renewal situations are the same. The possibility for continued funding of DMS institutes without automatic sunset places additional responsibility on the Division to monitor and constantly evaluate the performance of its institutes. Through regular review of its institute portfolio, DMS aims to ensure that all the supported institutes continue to be highly successful and of high impact to a large community.

The Division recently completed a lengthy and careful review of five of the DMS-supported institutes in response to proposals for noncompetitive renewal. As a result of this review, it was decided to give requested five-year renewal awards to ICERM, IPAM, and MSRI, to give a three-year phase-out award to MBI, and to give a two-year phase-out award to IMA.

The fact that the recent renewal process was noncompetitive meant that there was no possibility to submit proposals for entirely new ventures, and it also meant that the five institutes were not seen as competing against each other for a more limited number of slots. The review process is conscientious and deliberate, with several instances of input from the mathematical community. The review started with a joint panel that evaluated all five proposals and "graded" them individually as any panel does (but made no comparisons). This panel also made recommendations on whether or not to arrange a site visit to further assess each application. While there were significant differences in the "grades" assigned, all five institutes were recommended for site visits, which then took place in the fall of 2014. Each site visit team typically consisted of four external "visitors" and four DMS 
scientific staff members. The external visitors were responsible for furnishing a site visit report that was submitted to DMS immediately after the completion of each visit. These reports outlined the strengths and weaknesses of each institute as perceived by the external visitors; these reports made suggestions for changes; and, finally, each report made a recommendation to DMS concerning the continued funding of the particular institute. It should be pointed out that, unlike the "anonymous" panel that reviewed all the institute proposals, the members of the site visit teams are of course known to the institutes, and their names appear on the site visit reports.

Upon completion of the site visits, the information gathered-i.e., the panel reviews, the site visit reports, the impressions of the NSF program directors who had participated in the site visits, as well as information from the institute annual reports-was discussed extensively by the DMS Institute Management Team (a group of six program directors) and by the group of all DMS program directors. The Institute Management Team made a recommendation to the full group of program directors that was discussed and adopted at a meeting on December 3, 2014. This recommendation was to make the requested five-year awards, held to the current budget levels, to three of the institutes: namely, ICERM at Brown University, IPAM at UCLA, and MSRI in Berkeley. The same recommendation was to make a two-year phase-out award to the IMA at the University of Minnesota. At the end of those two years IMA will no longer receive DMS core funding. The fifth institute under review was MBI at Ohio State University. This is a mathematical biology institute, and as a result of the most recent review (but also following earlier reviews) it has become the strongly held belief of DMS that, after twelve years of "incubation" entirely supported by DMS, there is a need to broaden the reach of this potentially very important activity in such a way that units or agencies that provide funding for the biology community (for instance, the NSF Directorate for Biological Sciences or the National Institutes of Health) would be willing to serve as equal funding partners. While the feasibility of such joint arrangements is being investigated, it was decided to give MBI a three-year phase-out award. Should joint funding not prove feasible, the DMS core support of MBI will expire at the end of these three years.

\section{The Future of the DMS Institutes Program}

The Division of Mathematical Sciences is extremely supportive of its Mathematical Sciences Research Institutes program and views it as a strong, continuing component of its awards portfolio. DMS finds the institutes to be very important for numerous reasons: (1) their concentration periods, which help focus the attention of some of the best mathematical minds on problems of particular importance and timeliness; (2) their ability to reach a much wider community of US mathematicians than those reached by the DMS through its Individual Investigator program; (3) their significant contribution to workforce development; and (4) their capability for outreach to the general public. DMS is firmly committed to continued support of these important national resources. On the other hand, the DMS budget situation does not allow for continued relative growth of the institutes program similar to that seen in the past. The funding decisions recently taken should be seen as an expression of the DMS's desire to keep the institutes program dynamic and vibrant and able to respond to potential future demands for new activities within its current financial scope. In this context it may be relevant to note that there will be a call for (competitive) submission of proposals for Mathematical Sciences Research Institutes with a due date in early 2019.

\section{References}

[1] US Research Institutes in the Mathematical Sciences: Assessment and Perspectives (1999), Committee on US Mathematical Sciences Research Institutes, National Research Council, www. nap.edu/openbook. php?record_id=9449 